\section{CHAPTER 6 \\ The Sirens of Elea: Rationalism, Monism and Idealism in Spinoza}

YITZHAK MELAMED

The main thesis of Michael Della Rocca's outstanding Spinoza book (Della Rocca 2008a) is that at the very center of Spinoza's philosophy stands the Principle of Sufficient Reason (PSR): the stipulation that everything must be explainable or, in other words, the rejection of any brute facts. Della Rocca rightly ascribes to Spinoza a strong version of the PSR. It is not only that the actual existence and features of all things must be explicable, but even nonexistence-as well as the absence of any feature of any thing--demands an explanation. Della Rocca does not stop here, however. He feeds his PSR monster with some more powerful steroids and suggests that Spinoza advocates what he terms "the twofold use of the PSR." It is not only that everything must be explained and made intelligible, but it must ultimately be explained in terms of explicability or intelligibility itself. This twofold use of the PSR is the key to the entire book. Della Rocca's strategy throughout the book is to argue that any key feature of Spinoza's system-be it causality, inherence, essence, consciousness, existence, rejection of teleology, goodness or political right-must be explained, and ultimately it must be explained in terms of intelligibility. "Spinoza single-mindedly digs and digs until we find that the phenomenon in question is nothing but some form of intelligibility itself, of explicability itself" (see p. 71 above).

Della Rocca's book came out together with a cluster of articles in which he develops in detail his new reading of Spinoza. ${ }^{1}$ In one of these articles, he warns the reader: "Don't let me start" (Della Rocca 2010, 1). The train that is about to embark leads to very bizarre terrain, and thus one should think twice before embarking on the "PSR Express." In this chapter I argue that the train was hijacked. This was a perfect crime: without anyone noticing it, the engine driver diverted the train to a new route, and as with other perfect crimes, it is only the criminal himself who is capable of bringing about his own demiseas indeed he will. As I will later argue, Della Rocca's "PSR-on-steroids" will eventually cripple reason itself. But let us not run too fast-we'll start at the very beginning. I happily-or at least, so I think-board the "PSR Express." I believe Spinoza is strongly committed to the PSR and makes very significant use of this principle, but, unlike Della Rocca, I do not think the PSR is the key to all mysteries Spinozist, nor do I believe Spinoza was committed to the reductionist program of explaining all things through intelligibility (i.e. the second use of the PSR).

Della Rocca's exciting interpretation raises several deep, foundational, questions but unfortunately I can only address a few of them here. In the following I will concentrate on three issues related to Della Rocca's reading. I will first point out the non-trivial danger of misuse of the PSR, and then turn to examine the validity of Della Rocca's inference from the unavailability of explanations of facts to the rejection of the same facts. I will conclude with a critical examination of Della Rocca's claim that the PSR does not allow for any bifurcations in nature.

\section{On the Possible Misuse of the PSR}

The PSR is a powerful tool and, like any other powerful tool, it can be misused. Leonhard Euler (1707-1783), the great Swiss mathematician who was essentially sympathetic to the principle, warned against the "wretched abuse" of the PSR by those who "employ it so dexterously that by means of it they are in a condition to demonstrate whatever suits their purpose, and to demolish what ever is raised again them" (Euler 2009, 224). Euler was particularly alarmed by proofs which rely on the PSR to achieve nothing over and above a petitio principii (or question-begging argument) (Euler 2009, 226). But Spinòza, himself, pointed out the tight connection between a rushed use of the PSR and religious superstition. Consider the following example presented by Spinoza in the appendix to Part One of the Ethics:

If a stone has fallen from a roof onto someone's head and killed him, they will show, in the following way, that the stone fell in order to kill the man. For if it did not fall to that end, God willing it, how could so many circumstances have concurred by chance (for often many circumstances do concur at once)? Perhaps you will answer that it happened because the wind was blowing hard and the man was walking that way. But they will persist: why was the wind blowing hard at that time? Why was the man walking that way at that same time? If you answer again that the wind arose then because on the preceding day, while the weather was still calm 
the sea began to toss, and that the man had been invited by a friend, they will press on-for there is no end to the questions which can be asked. but why was the sea tossing? Why was the man invited at just that time? And so they will not stop asking for the causes of causes until you take refuge in the will of God, i.e. the sanctuary of ignorance.

( lapp; Spinoza 1925, II.80-1)

There are three striking features of the superstitious that contrive together to produce the phenomenon Spinoza examines here. First, the superstitious adhere to the PSR in a very strict and systematic manner, or as Spinoza writes "they will not stop asking for the causes" of things. Second, the superstitious are not willing to allow for coincidences, i.e. the concurrence of events whose cause (i.e. the cause of the concurrence) is not easy to explain, and perhaps even impossible to explain, by appealing only to the causes of one or the other concurring events. Finally, the superstitious are satisfied by a unifying and global explanation--the will of God-which upon close examination turns out to be nothing but ignorance (insofar as God's will is taken to be arbitrary or self-explanatory).

Similarly, in chapter 9 of the Theological Political Treatise, Spinoza mocks those who believe that every slight abnormality in the Hebrew of the biblical text discloses great secrets and mysteries (Spinoza 1925, III.135). Obviously, Spinoza does believe that all features of the biblical text--just like any features of any text, or anything--deserve an explanation. Yet, the explanation may not be available to us, not because it involve great secrets, but rather because we know very little about the precise causal history of almost any particular thing. While the superstitious do have the right urge to insist on asking conscientiously about the causes of things, their use of the PSR is both too strong and too weak: too strong because when no natural explanation is readily available to them, they conclude that there is no natural explanation, and too weak, because they shelter "the Will of God" from the policing authority of the PSR (i.e. it is not subject to their demand for explanation).

What should we learn from all this? Not much, at this point. We should just be aware of the rather obvious possibility that the PSR can be misused.

\section{"Unexplainable"}

Throughout his book Della Rocca frequently makes truly insightful and illuminating use of the PSR to help motivate various positions of Spinoza's, yet, in several crucial places in the book, he uses the PSR in a manner I find to be flawed. ${ }^{2}$ In all of these places Della Rocca attempts to rule out a certain putative state of affairs $F$, by arguing that if $F$ were the case, $F$ would be--or would bring about-a brute fact, and hence must be rejected since the PSR does not allow for brute facts. Della Rocca uses the same strategy in all of these cases: First, he presents $F$, the putative fact which he intends to rule out using the PSR. Then, he presents two or three explanations that could motivate or justify F, and shows that none of the suggested explanations succeeds in motivating F-so far, so good. At this point comes the announcement that "no explanation of $F$ is available." But if $F$ is not explicable, it is a brute fact, and hence must be rejected by force of the PSR.

The problem with this line of argument is that Della Rocca seems to argue from:

(1) we have no explanation of $F$

to

(2) $F$ is not explainable

or, in slightly different fashion, from

(3) we have no explanation of $F$

to,

(4) F seems to be unexplainable

to,

(5) F is a brute fact.

Such arguments fail to appreciate the modality required for the proper use of the PSR. To claim that so far we have not found any explanation for $F$ is one thing. To claim that there is no possible explanation for $\mathrm{F}$ is a completely different thing. As an example of a proper use of arguments from inexplicable facts, consider Leibniz's argument-in his correspondence with Clarke-against the possibility of absolute space. Here, too, Leibniz uses the PSR in order to rule out a certain state of affairs: the existence of absolute, empty space. Leibniz's argument is roughly the following: Suppose space could exist without anything in it. Then, God, when he comes to decide where in space to create the world, could have no reason to create the world in any particular location, because all spatial locations in empty space are qualitatively indiscernible. Whatever reason God could have to create the world at place $\mathrm{P} 1$, should equally pertain to any other place (in absolute space) $\mathrm{P} 2$, since there cannot be any qualitative difference between $\mathrm{P} 1$ and $\mathrm{P} 2$. Thus, God cannot have a reason to create the world in one place rather than another (AG 324). Notice that the argument does not rely on the claim that so far we have not found a reason that 
could motivate God to create the world in P1 rather than P2. Leibniz's argument relies on the far stronger claim that there cannot be a reason for God to create the world in P1 rather than P2. In other words, Leibniz argues from:

(6) there cannot be reason for $F$

to

(7) $F$ is a brute fact

While the transition from (6) to (7) is valid, the transitions from (1) to (2) and (3) to (5) are not. It is perfectly possible (and in fact quite common), that no explanation for a certain fact $\mathrm{F}$ is available to us right now, but $\mathrm{F}$ is still perfectly explicable (and the explanation might even become accessible to us in the future). In other words, in order to be valid, the argument must positively show that it exhausted all possible explanations, and that none of these explanations is successful. Proving exhaustibility is, in most cases, quite a daunting task, and demands more work than merely ruling out three or four explanations.

In order not to leave these severe allegations (e.g. of a "hijacked train" etc.) up in the air, let us look quickly at two texts where, I believe, Della Rocca makes an unwarranted use of the PSR. In the first text, the author attempts to show that for Spinoza all mental states are representational. Della Rocca presents the view he attempts to rule out-that for Spinoza some mental states are representational while others are not--and asks by virtue of what both representational and non-representational states are mental. He rightly disqualifies one explanation and then restates the question:

What is it in virtue of which $A$ and $B$ are both thinking? Perhaps they are both mental in virtue of the fact that they causally interact with mental states. But this won't get us very far. For Spinoza, two things interact only because they belong to the same attribute, for example the attribute of thought. I know of no other plausibly Spinozistic way to answer the question what is in virtue of which $A$, a representational mental state, and $B$, a nonrepresentational mental state, are both thinking. Thus the existence of such disparate mental states would involve a brute fact and so be unacceptable.

$(2008 \mathrm{a}, 121)$

Notice how Della Rocca moves from the claim that "I know no other plausibly Spinozistic" explanation for the disparity of mental states, to the conclusion that such a disparity is a brute fact. This move is, in my mind, illicit.

Della Rocca could defend his view by suggesting that while his argument may fall short of proving his point conclusively, it still shifts the burden of proof to the opponent of the twofold use of the PSR. Perhaps, so Della Rocca's argument would go, we should tentatively consider $\mathrm{F}$ (the fact for which we have not yet found any explanation), a brute fact, and thus tentatively reject it. ${ }^{3}$ I doubt this defense strategy could work. There are far too many things whose explanation is not transparent to us. I, for one, do not know the complete explanation for almost anything I encounter. Should I therefore tentatively conclude that these things do not exist (as long as I have no complete explanation for each)? The counter-commonsense nature of such a radical form of skepticism seems to me much less troubling (since Spinoza frequently rejects common sense) than the inconsistency of this view with Spinoza's disparaging rejection of skepticism. ${ }^{4}$ Consider, for example, Spinoza's claim in $2 \mathrm{p} 13 \mathrm{c}$ and $2 \mathrm{p} 17 \mathrm{~s}$ ) that "the human body exists as we are aware [sentimus] of it." In these passages Spinoza does not require that we know the complete explanation of the human body (this could be achieved only rarely through the Third Kind of Knowledge), but rather feels comfortable enough to pronounce that the human body exists relying merely on our awareness of the body.

There is an even stronger consideration against the inference from tentative lack of explanation for $F$ to the tentative rejection of F, but here I can only point out the direction of that argument. In many cases we cannot provide an adequate explanation for either F or its opposite. Thus, if we follow Della Rocca's line of defense, we should conclude that both F (insofar as we have no adequate explanation for not-F) and its opposite (insofar as we have no adequate explanation for $\mathrm{F}$ ) are the case, which is clearly absurd.

Another instance in which Della Rocca relies on the unavailability of explanation to rule out a certain state of affairs is in his discussion of divine teleology in Spinoza. Here, I think, the temptation of the easy "no explanation is available" argument leads Della Rocca to an imprecise representation of Spinoza's argument against divine teleology.

Della Rocca's aim in the following passage is to motivate Spinoza's rejection of divine teleology, a view which he cashes out narrowly as a rejection of any case in which God acts for the sake of any particular finite being $x$. Della Rocca points out (rightly) that every finite mode $x$ is part of a strictly necessary and deterministic causal chain of finite modes and then argues that God cannot act for the sake of one of these finite things since God cannot arbitrarily privilege one link in the chain over the other:

$x$, the finite mode in question, is necessarily in the midst of a series of finite causes and effects, but, we are supposing, $x$ nonetheless outstrips other modes in importance to God. Why does God privilege $x$ in this way instead of privileging some other finite mode, say, certain of $x$ 's causes or $x$ 's effects? $X$ is neither the culmination of the series of finite modes, nor is it the starting point. So these natural reasons for privileging $x$ are not present. Nor can it be said that God privileges $x$ because $x$ is more like 
God than other finite modes. For each divine-like quality that $x$ has, there will be other, perhaps infinitely many other, finite modes that have those divine-like qualities to a higher degree ... For this reason, any privileging of $x$ in particular would seem to be arbitrary, a brute fact. And, as such, Spinoza would reject it.

$(2008 a, 85-6)$

Here, too, Della Rocca considers two explanations that could justify the view he is arguing against. He shows that neither explanation works, and concludes that in the absence of any explanation, the privileging of $x$ is a brute fact. But, here too, as far as I can see, the transition from "no explanation for F is available" to " $F$ is unexplainable" is faulty.

Della Rocca's focus on the question of whether God could privilege one finite mode over the other leads him to misformulate Spinoza's critique of divine teleology. Spinoza does not limit his critique of divine teleology to the rejection of divine action for the sake of a finite thing; rather, for Spinoza, God acts for the sake of no one, not even for His own sake (see lapp; Spinoza 1925, II.80.23). Thus, unjustified privileging of one item over another does not seem to provide the motivation for Spinoza's rejection of divine teleology. God is clearly and justly privileged in comparison to the finite modes, but Spinoza's God does not act for the sake of himself as well. Since brute privileging does not seem to be the primary motivation behind Spinoza's critique of divine teleology we must seek an explanation elsewhere.

The lesson I suggest we draw from the teleology issue is that not finding an explanation for a certain fact does not warrant rejecting it as a brute fact. In the case of teleology, we find a purported brute privileging which, upon examination, turns out to be not-brute privileging. Yet Spinoza's refusal to make his God act for the sake of a justly privileged entity (such as God himself) shows that the rejection of brute facts cannot provide the principled explanation for Spinoza's rejection of divine teleology.

\section{Bifurcations and Radical Monism}

At the opening of his book, Della Rocca briefly explains Spinoza's naturalism as "the view that there are no illegitimate bifurcations in reality" (see p. 74 above). It is not that difficult to agree with the claim that there are no illegitimate bifurcations in reality, but the real question is whether there are legitimate bifurcations in reality, and Della Rocca seems to me to be tempted by the Sirens of Elea, and defends the far stronger claim that rejects any bifurcations in reality, tout court.

One crucial place where this bold view surfaces is in Della Rocca's attempt to show that, for Spinoza, inherence and causation are strictly identical. According to Della Rocca, both inherence and causation are relations of conceptual dependence (I do not agree with this view, but I'll grant it for the sake of the argument). ${ }^{5}$ At this point Della Rocca presses the following question:

What makes [inherence and causation] distinct? This is a pertinent question, because, after all, they do have something in common: they are both kinds of conceptual dependence. Wherein do they differ? It's hard to see the difference here as anything other than a brute fact. There seems to be no way to elucidate the difference or to explain what it consists in except to say that mere causal dependence is the kind of conceptual dependence that, for example, bodies bear to God . . . and inherence is that kind of conceptual dependence that, for example, states of bodies bear to those bodies. Such an answer merely states that there is a difference between inherence and mere causation without explaining what the difference consists in.

$(2008 \mathrm{a}, 76-7)$

I have argued elsewhere that the identification of inherence and causation is inconsistent with some of Spinoza's most important metaphysical doctrines. ${ }^{6}$ For shortness of space I will avoid repeating these arguments here, but let me present here four other issues related to the internal consistency of Della Rocca's crusade against bifurcations.

First, one possible answer to the question of what makes inherence and causation distinct is that their concepts make them what they are and ground the distinction between them. Oddly enough, in spite of Della Rocca's battle against primitive distinctions, he is, on occasion, amenable to analytic explanations that ground the qualities of things in their essences, or natures, or concepts, and stop there. Consider the following passage in which Della Rocca attempts to show that to represent a thing $x$ is to represent its essence:

Given that $\mathrm{E}$ is the essence of $x$, and given that for Spinoza, as we have seen, the essence of a thing simply amounts to the very intelligibility of the thing, the way in which the thing must be understood, it follows that to ask why $x$ has $E$ is as silly as asking why squares have four equal sides. It's part of the essence, and indeed part of the concept, of squares to have four equal sides-this is how squares must be understood. In the same way, it's just $x$ 's concept or essence to have $E$.

(2008a, 97; italics added)

It is somewhat unclear to me why it is sillier to ask why a square has four sides, than to ask why an inherence relation is a relation in which one thing is in another. Let's compare the two cases. Inherence and causation are both allegedly relations of conceptual dependence. Squares and triangles are both polygons. We can ask what distinguishes squares from triangles and the answer we 
are likely to get will appeal to the very essence of each (i.e. "squares have four sides," etc.). Similarly, we may ask what distinguishes inherence from causation and the answer we are likely to get will appeal to the very essence of each relation (i.e. "an inherence relation is one in which $x$ is in $y$," etc.). Where, precisely, is the difference between the two cases? What kind of analytic explanations, which virtually just restate the essence of the thing, is Della Rocca willing to accept and what kind is he not willing to accept? On its face, the distinction between the two cases seems to be just brute and arbitrary.

Second, for all I can tell, Della Rocca's argument against bifurcation seems to commit him to an extremely radical version of monism that rejects any kind of bifurcations and allows for the reality of merely one indivisible thing, and merely one concept. Here is a brief outline of the argument leading to this conclusion.?

Suppose there were any two distinct concepts, $\mathrm{C} 1$ and $\mathrm{C} 2$. We could legitimately ask by what virtue $\mathrm{C} 1$ is what it is and not $\mathrm{C} 2$, and why $\mathrm{C} 2$ is what it is and not $\mathrm{C} 1 . \mathrm{C} 1$ and $\mathrm{C} 2$ have something important in common: we assumed that they are both concepts (neither giraffes nor elephants!). Why are they different then? Wherein lies the difference? Of course, we can push the question slightly by saying that $\mathrm{C} 1$ has quality $\mathrm{Q}$ and $\mathrm{C} 2$ doesn't, but here we should employ the same strategy Della Rocca uses constantly against "illegitimate" bifurcations, and ask why $\mathrm{C} 1$ has $\mathrm{Q}$ and $\mathrm{C} 2$ doesn't. (They are both concepts! Where does this difference come from?) In this manner, we are not likely ever to reach a satisfactory explanation, and hence the difference between $\mathrm{C} 1$ and C2 would seem to be a brute fact.

Similarly, since for Spinoza, natura naturans (i.e. the substance) is strictly indivisible, we could (and should) ask where the diversity of things comes from. If at the very beginning of things-at the level of substance--there is strict unity and indivisibility, we should detect the first appearance of diversity, and ask by virtue of what we have two things that are distinct. (In this case, I think the question is very powerful since we can show that the only possible explanation -i.e. natura naturans, from which the diversity sprung-is strictly indivisible and thus cannot explain the diversity. Thus, I take the last question to be a genuine and serious problem for Spinoza, not only for Della Rocca. $)^{8}$

If we take the above arguments against bifurcation seriously, the ensuing view is the acosmist interpretation of Spinoza, suggested by the German Idealists (Maimon and Hegel), according to which Spinoza considered any diversity (the diversity of modes as well as the diversity of attributes) a mere illusion. Let me note that Hegel takes a variant of the PSR - the "ex nihilo nihil fit" formula- to be the main motivation behind Spinoza's alleged acosmism (Hegel 1969,84 ; Hegel 1991, 144). While I find the acosmist reading fascinating, I believe that in the final account it has to be rejected since it conflicts with far too many important doctrines of Spinoza's. Consider, for example, Spinoza's claims in E1pl6d that it is the intellect that infers the modes from God's nature.
For Spinoza, the intellect never errs, but were the modes unreal or illusory, the inference of the intellect would clearly be faulty-contrary to Spinoza's view. ${ }^{9}$ To the best of my knowledge, Della Rocca does not wish to endorse To the acosmist interpretation, but rather a certain moderate version of it, according to which modes are neither fully real, nor are they illusory. ${ }^{10}$ This view is correct in a very trivial sense insofar as modes are less ill than the substance (the reality of modes depends on the reality of the substance) ${ }^{11}$ However, Della Rocca also suggests that the limited reality of modes rect the subreflects the fact that modes are not fully conceived and fully caused by the substance (for Della Rocca, degrees of reality reflect degrees of conceivability). ${ }^{12}$ This, I think, is not consistent with Spinoza's claim in E1p16d that the modes are inferred by the intellect. Were the modes not fully conceived, the inference of the intellect would have to be faulty.

Third, one of the most interesting results of the claim that only the substance is fully real is that it forces us to reevaluate the status of relations in Spinoza, most crucially the relation of conception. ${ }^{13}$ If there is only one fully real thing, and plurality pertains only to partly real things, it would make sense that rationality should be exhibited fully at the level of the fully real entity (and that rationality should be exhibity arty real plurality of things). Let's have a closer look at the doings of our fully real entity.

On first sight, our one indivisible entity may appear somewhat boring. Just like the Aristotelian Prime Mover, it keeps on conceiving itself, and conceiv ing itself, and-surprise, surprise-once again conceiving itself. "Well, what's wrong with that?" you might say, "We have long suspected that heaven is pretty boring." One problem is that it is not at all clear that our entity is even entitled to this kind of activity. According to Della Rocca, there is really only one relation: conceivability is causation is inherence. (If there were any other relation, we would ask, "By virtue of what is it distinct from conceivability?" etc.)

But wait, why is conceivability a two-place relation and not, say, a monadic predicate, such as " $x$ is conceived"? Since there is only one entity in our fully real realm, it would make just as much sense to cash out rationality as a monadic predicate, " $x$ is conceived" or " $x$ is conceiving" (which one? and how can we decide between the two?), or as apolyadic two-place reflexive relation " $x$ is conceived through $x$ " or as a zillion-place polyadic relation, " $x$ is conceived through $x$, through $x, \ldots$ through $x$." There seems to be no reason to privilege a two-place reflexive relation of conceivability over monadic predicate of conceivability, or the other way around. Whatever choice we make would be a brute fact.

But let's assume for a minute that we can justify a choice of one of the disjuncts. Let's say the monadic predicate. Our fully real entity has the one monadic predicate of " $x$ is conceiving." Recall that there are no other concepts (on the pain of there being brute facts: "what makes them distinct from conceiving?"). Here, then, is our paradigm of pure rationality and explanation: "The 
substance is conceiving." What precisely does this explain? How poor does this radical, rock-smashing, rationality end up being?

Finally, let me note that if we push the bifurcation argument slightly further ahead, we could ask: in virtue of what do we distinguish between the subject ("substance") and its predicate ("is conceiving")? Were they strictly the same, I cannot see how in such a world there would be any movement or thought at all. Such a world would be far too poor, far too thin, to entertain thought. Recall that for Spinoza the excellence of minds is a function of their complexity, which reflects the complexity of the parallel bodies (2p13s). When we detach the substance from its modes we seem to get an entity with infinitesimal complexity and an extremely dumb thought. ${ }^{14}$ We can reach the same conclusion from a slightly different angle. Since for Spinoza the only vehicles of thought are ideas (2a3 and 2p11d), and ideas are modes (2a3), it would seem that if the PSR leads to the unreality (or limited reality) of modes, it ends up proving the unreality (or limited reality) of ideas and thought itself.

The last two points seem, to me, cut not only against Della Rocca's view as an interpretation of Spinoza, but even against an attempt to present this view as an independent venture, going beyond Spinoza. These two points show that the radical, strict, rationalism of the twofold use of the PSR ends up undermining and crippling reason itself. As I warned you at the beginning of this chapter, it was none but the capable, yet PSR-intoxicated, engine driver of our hijacked train who brought about his, and reason's, own demise.

\section{Acknowledgement}

An early version of this chapter was read at an author meets critics session on Della Rocca's book in the 2010 meeting of the Eastern division of the American Philosophical Association. I would like to thank John Brandau, Don Garrett, Mike LeBuffe, John Morrison, Alan Nelson, Sam Newlands, Oded Schechter, and especially, Michael Della Rocca, for their most helpful comments on earlier versions of this chapter.

\section{Notes}

1. See Della Rocca $(2003,2008$ b, 2010, and forthcoming).

2. I address below the two cases of representation and teleology. For another crucial example of this line of argument, Della Rocca's identification of causation and inherence in Spinoza, see Della Rocca $(2008 \mathrm{a}, 65)$.

3. Della Rocca actually suggested a response in this spirit in a session on his book at the Eastern

Division meeting of the American Philosophical Association in December 2010.

4. See Spinoza's Treatise on the Emendation of the Intellect, $\$ \$ 47-48$; Spinoza $1985,22$.

5. For Della Rocca's reduction of causation to conceivability see p. 74 above.

6. See Melamed (2012b)

. Della Rocca seems to embrace this conclusion in Della Rocca, forthcoming

8. I address this problem in Melamed (2012a).
9. On the German Idealists' acosmist interpretation of Spinoza, see Melamed(2010). For a detailed critique of the acosmist reading, see Melamed (2012a).

0. See DellaRocca (forthcoming, Section III).

1. Consider, for example, an axiom Spinoza adopts from Descartes: "A substance has more reality than an accident or mode" (DPP Part I, Axiom 4; Spinoza 1925, I.154.27).

12. See Della Rocca (forthcoming), Section III, and Della Rocca (2008a, 263).

13. Della Rocca develops and embraces some of the implications I discuss below in Della Rocca (forthcoming).

14. While the human mind can conceive many things (2p14), the substance detached from its modes conceives nothing but one thing: itself. 